\title{
Successful First-in-Man Concomitant Transapical Transcatheter Aortic and Mitral Valve Replacements for Severe Native Aortic and Mitral Valve Stenosis Using the Edwards Certitude Delivery System
}

\author{
Anwar Tandar, MD'1, Jason P. Glotzbach, MD², Frederick G.P. Welt, MD'1, Vikas Sharma, MD², Kelsee \\ Browning, AGNP-C' , Craig H. Selzman, MD², Abdulfattah Saidi, MD ${ }^{1 *}$, David A. Bull, MD² \\ ${ }^{1}$ Division of Cardiovascular Medicine, University of Utah School of Medicine, Salt Lake City, Utah, United States \\ ${ }^{2}$ Division of Cardiothoracic Surgery, University of Utah School of Medicine, Salt Lake City, Utah, United States
}

\begin{abstract}
Transcatheter aortic valve replacement (TAVR) has become the treatment of choice for high or intermediate risk patients with symptomatic severe aortic stenosis. Transcatheter mitral valve replacement (TMVR) for native mitral stenosis is still under investigation in clinical trials. Results from a global registry, however, show that TMVR in patients with severe mitral annulus calcification is feasible but associated with significant adverse events. Simultaneous TAVR and TMVR on native valves has only been reported twice. Here, we report the first case of simultaneous TAVR and TMVR for native aortic and mitral stenosis using the Edwards Certitude transapical delivery system.

Copyright (c) 2017 Science International Corp.
\end{abstract}

\section{Key Words}

Native aortic stenosis - Native mitral stenosis • Simultaneous - Double valve - Transcatheter valve replacement $•$ Transapical approach

\section{Introduction}

Transcatheter aortic valve replacement (TAVR)

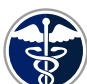

Fax +1 2037853346

E-Mail: jshd@scienceinternational.org

http://structuralheartdisease.org/

\author{
(C) 2017 Journal of Structural Heart Disease \\ Published by Science International Corp. \\ ISSN 2326-4004 \\ Accessible online at: \\ http://structuralheartdisease.org/
}

has emerged as the treatment of choice for patients with severe aortic stenosis who are deemed to be at high or intermediate risk for surgery [1, 2]. Transcatheter mitral valve replacement (TMVR) for inoperable severe calcific native mitral stenosis is currently under investigation in clinical trials [3]. Results from a global registry show that TMVR, when performed in highly selected patients, results in significant adverse events [4]. Simultaneous TAVR and TMVR of stenotic native valves has only been reported in two cases $[5,6]$. Here, we report the first case of simultaneous TAVR and TMVR for severely stenotic native aortic and mitral valves in a high-risk patient using the Edwards Certitude transapical delivery system (Edwards Lifesciences, Irvine, CA, USA) (Figure 1).

\section{Case Presentation}

The patient was a 71-year-old man with symptomatic severe aortic stenosis (mean gradient, $53 \mathrm{mmHg}$; aortic valve area, $0.7 \mathrm{~cm}^{2}$; maximum aortic valve velocity, $4.1 \mathrm{~m} / \mathrm{s}$; Figure 2 and Figure 3 ) and heavily calcified severe mitral stenosis (mean gradient, 12 $\mathrm{mmHg}$; mitral valve area, $1 \mathrm{~cm}^{2}$; Figure 4 and Figure

* Corresponding Author:

Abdulfattah Saidi, MD

Division of Cardiovascular Medicine

University of Utah School of Medicine

50 North Medical Drive, Salt Lake City, UT 84132, USA

Tel. +1 801647 2390; Fax: +1 801585 3362; E-Mail: abdulfattah.saidi@hsc.utah.edu 


\section{Edwards Certitude Delivery System}

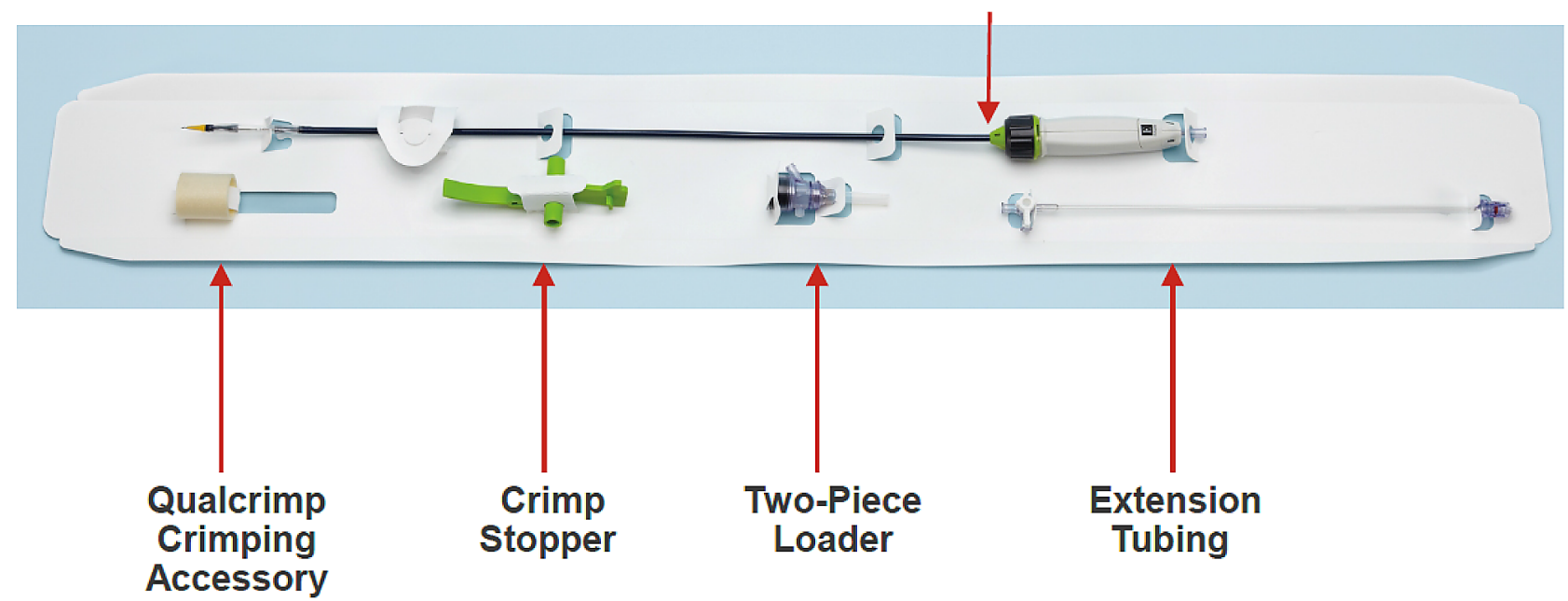

Figure 1. Edwards Certitude delivery system.

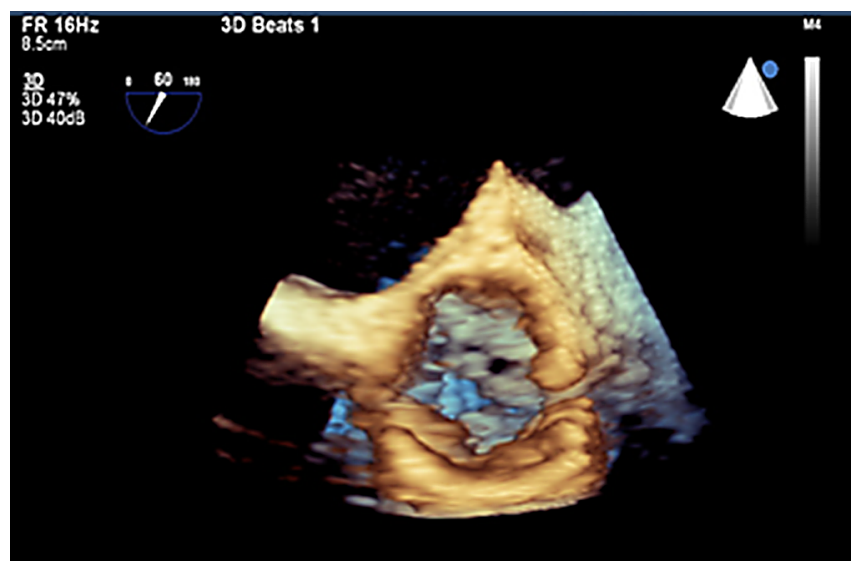

Figure 2. Three-dimensional TEE showing a heavily calcified aortic valve with severe stenosis.

5) with a Wilkins score of 12 and mean pulmonary artery pressure of $43 \mathrm{mmHg}$. His left ventricular ejection fraction was 44\%, and he showed Class III New York Heart Association symptoms. His medical history also included coronary disease status post-coronary artery bypass graft, peripheral artery disease status post-femoral-femoral artery bypass, porcelain aorta, severe chronic obstructive pulmonary disease, type II diabetes mellitus, and sick sinus syndrome.

After evaluation by a multidisciplinary heart team, the patient was deemed to be a prohibitively high-

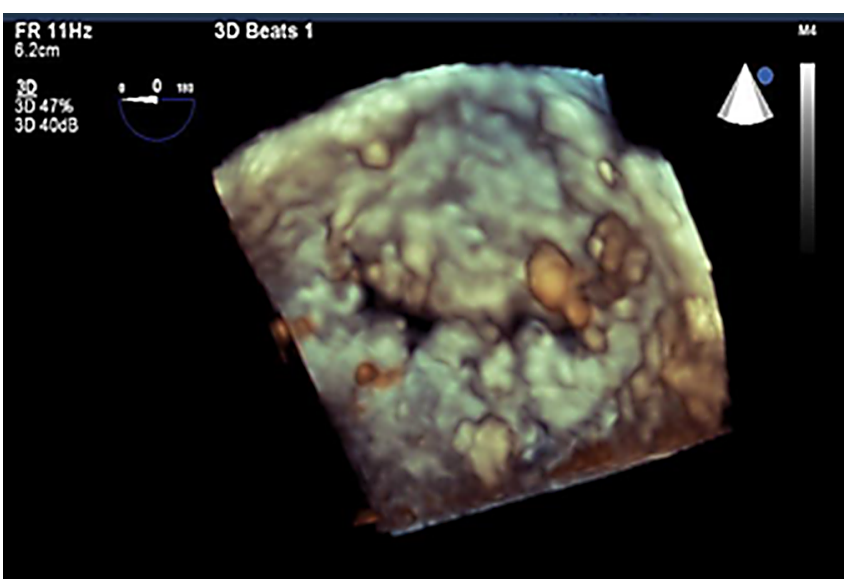

Figure 3. TEE short axis view showing a heavily calcified aortic valve.

risk candidate for surgical aortic valve replacement due to a Society of Thoracic Surgeons mortality risk score greater than $10 \%$ and the presence of a porcelain aorta on imaging studies. Balloon mitral valvuloplasty was contraindicated due to a high Wilkins score. Therefore, we made the decision to proceed with simultaneous TAVR and TMVR.

Valve analysis was performed using helical computed axial tomography (CT) scanning with 3 mensio Structural Heart (3mensio Medical Imaging BV, Bilthoven, Netherlands) and OsiriX three-dimensional 

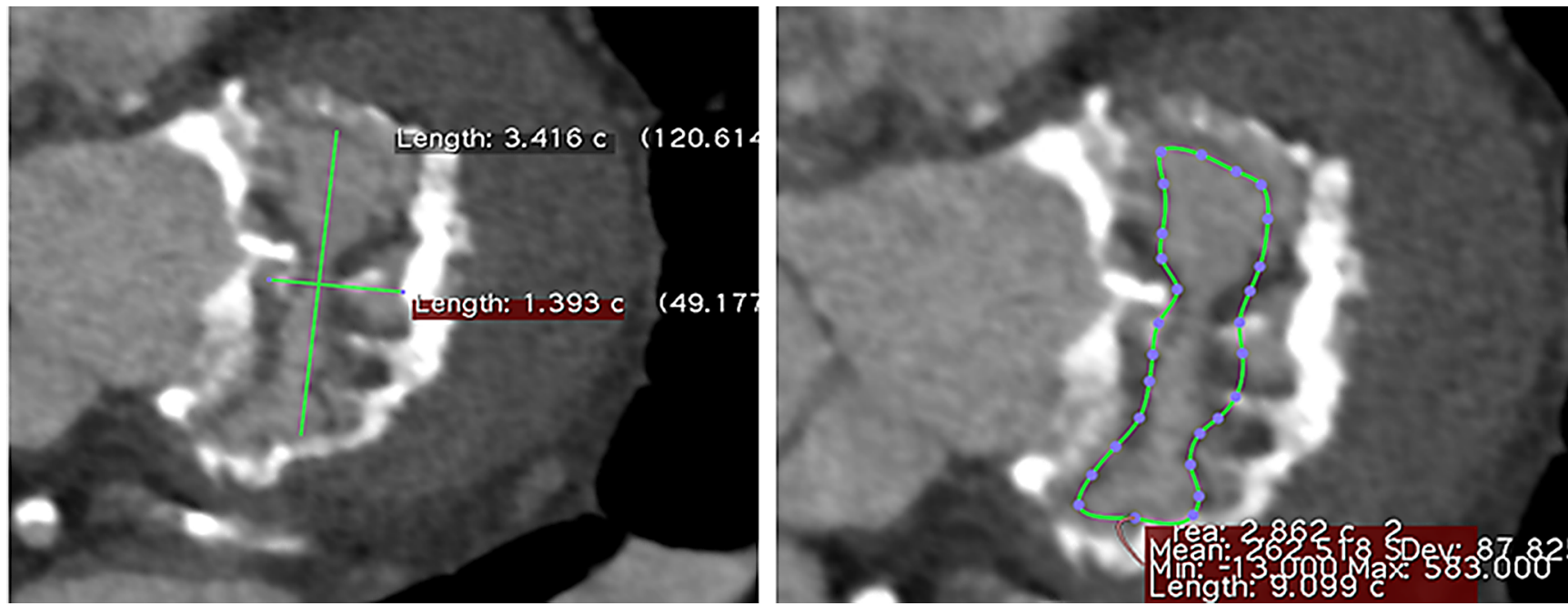

Figure 4. Three-dimensional TEE showing a heavily calcified mitral valve with severe stenosis..

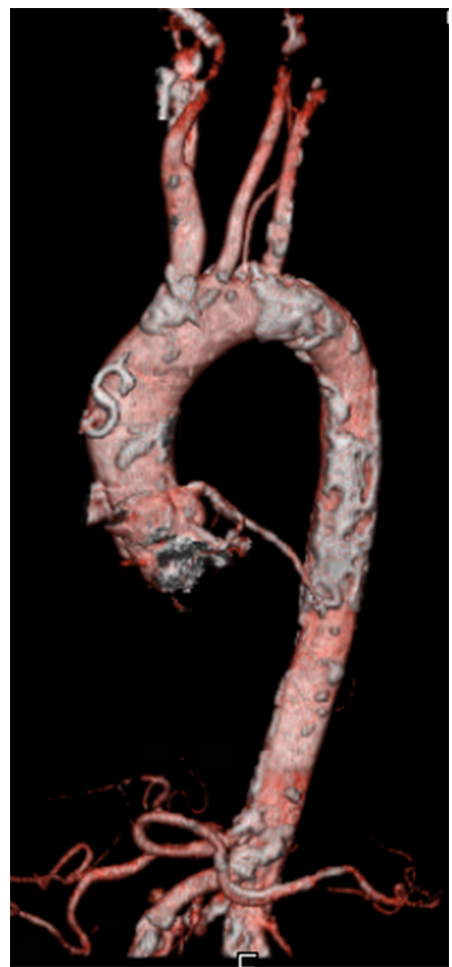

Figure 5. TEE four chamber view with color doppler showing severe mitral stenosis.

reconstruction software (Pixmeo SARL, Bernex, Switzerland). This analysis demonstrated an aortic annulus area of $480 \mathrm{~mm}^{2}$, which was suitable for a $26-\mathrm{mm}$ Edwards SAPIEN 3 (Edwards Lifesciences, Irvine, CA, USA) valve. The mitral valve area was $286 \mathrm{~mm}^{2}$, which was suitable for a 29-mm Edwards SAPIEN 3 valve.

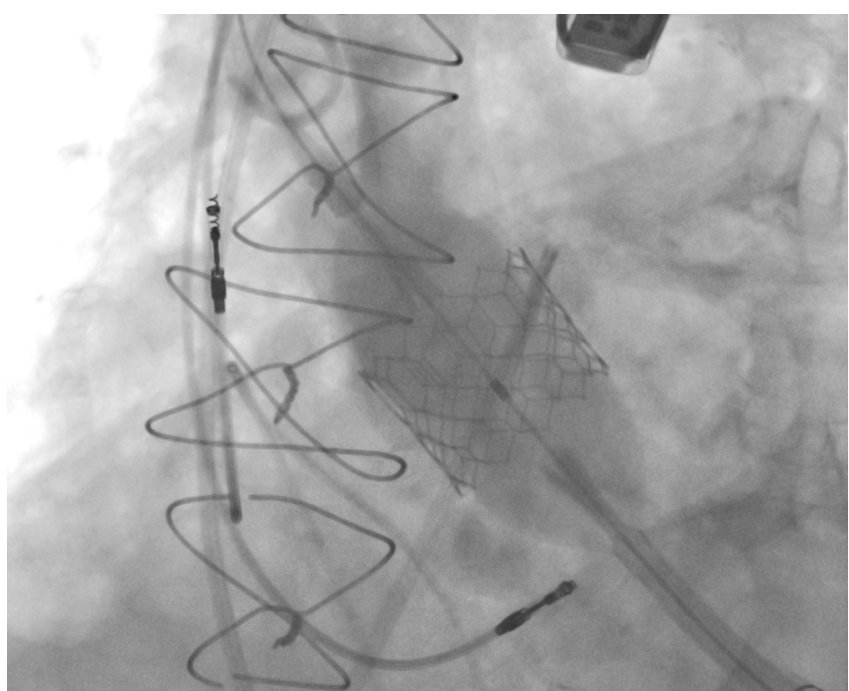

Figure 6. Fluoroscopy clip showing deployment of the SAPIEN 3 valve in the aortic position.

The CT scan also showed a porcelain aorta.

The procedure took place under general anesthesia in a hybrid operating room. A Certitude delivery system was inserted into the apex through a limited left anterior thoracotomy utilizing 2-0 plegeted braided polyester sutures as mattress pursestrings (Ethicon, Somerville, NJ, USA). A 0.035" guidewire was advanced into the ascending aorta and then exchanged with an Extra Stiff Amplatz wire. The 26-mm SAPIEN 3 valve was advanced and deployed during rapid pacing (Figure 6). Transesophageal echocardiography (TEE) showed that the prosthesis was in an 


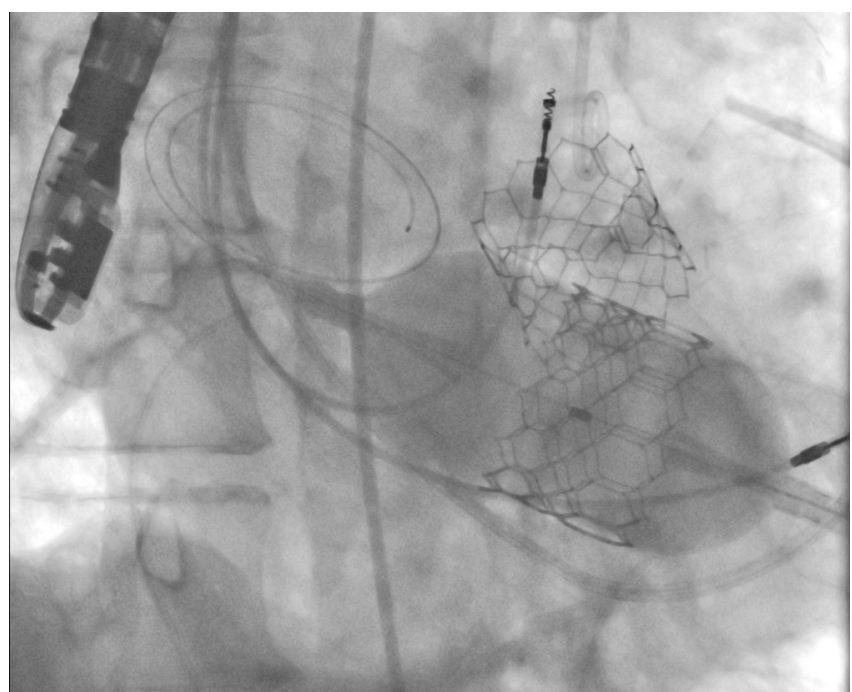

Figure 7. TEE biplane view of the aortic valve showing the SAPIEN 3 valve in the appropriate aortic position.

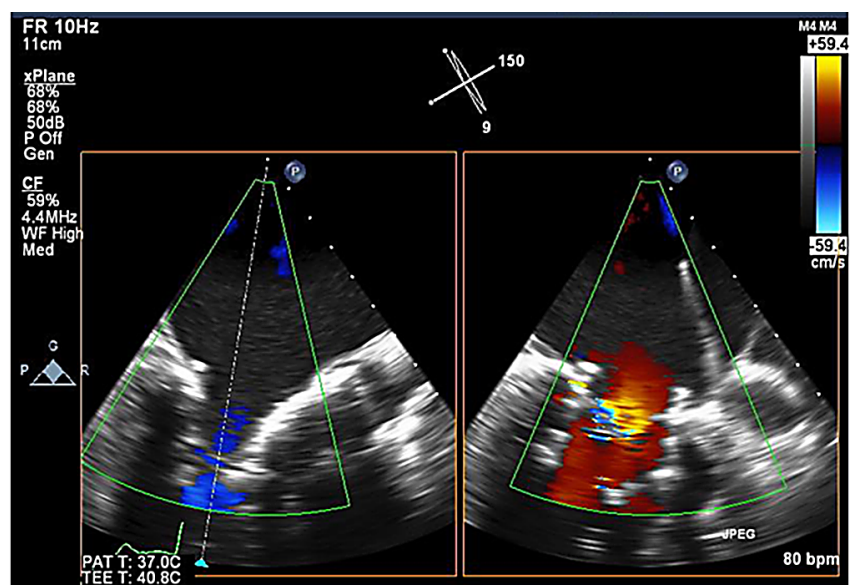

Figure 8. Fluoroscopy clip showing deployment of the inverted SAPIEN 3 valve in the mitral position.

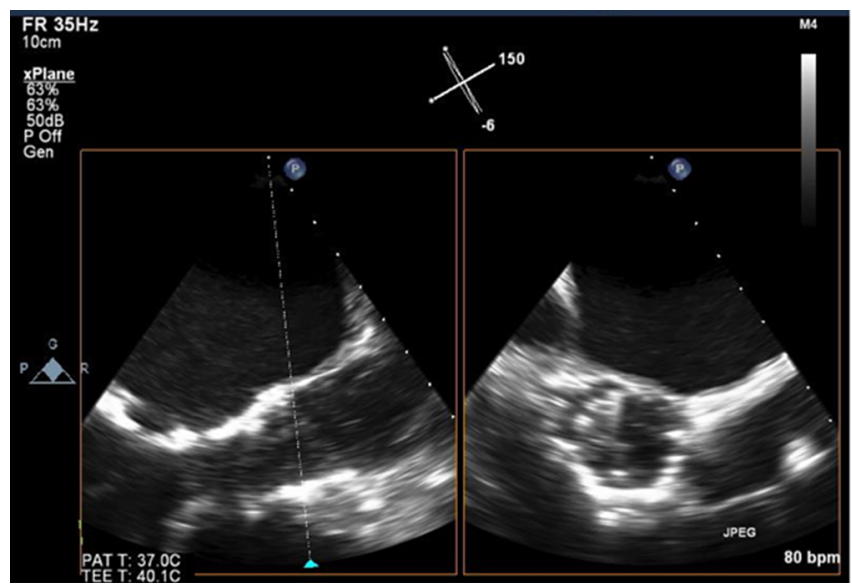

Figure 9. TEE showing the inverted SAPIEN 3 valve in the appropriate mitral position. optimal position without paravalvular leak (Figure 7). The mean gradient across the prosthetic valve was $5.7 \mathrm{mmHg}$.

Subsequently, the TAVR delivery system was removed, and the Certitude sheath was kept in place. A $0.035^{\prime \prime}$ straight-tip wire was used to cross the mitral valve and then exchanged with an Inoue wire. To achieve maximum expansion, $4 \mathrm{~mL}$ was added to the 29-mm SAPIEN 3 balloon. A coplanar fluoroscopic view was obtained using the mitral annular calcification as a landmark. The valve was deployed during rapid pacing using fluoroscopic and live TEE guidance (Figure 8). TEE showed that the prosthesis was in an optimal position (Figure 9), with trivial paravalvular leak and a mean gradient of $3.5 \mathrm{mmHg}$. The left ventricle outflow tract gradient was $12 \mathrm{mmHg}$. Postdilation with an additional $2 \mathrm{~mL}$ (total of $6 \mathrm{~mL}$ ) was performed to flair the atrial side of the Sapien valve and minimize the risk of valve migration. Prior to discharge (i.e., 5 days after the procedure), transthoracic echocardiography showed normal function of both prostheses without paravalvular leaks. At 2-month follow-up, the patient continued to do well. Follow-up transthoracic echocardiography showed no changes compared with prior study.

\section{Discussion}

TAVR has been found to be non-inferior to surgical aortic valve replacement in patients with severe atrial stenosis deemed to be at high or intermediate surgical risk [1, 2]. These patients often have concomitant mitral stenosis with a high Wilkins score, barring them from mitral balloon valvuloplasty. The option of performing TMVR of native mitral stenosis at the same time as TAVR, although not previously studied, has been reported in two cases $[5,6]$. To the best of our knowledge, this is the first simultaneous TAVR and TMVR of native aortic and mitral valves stenoses utilizing a single transapical access with the Edwards Certitude delivery system.

Because is a complex and novel approach, selecting the appropriate candidate is key for success of this procedure. It is of utmost importance to obtain accurate measurements of both aortic and mitral annuli and to select the appropriate prosthesis size and minimize the risk of interference given the anatomi- 
cal proximity of the two valves.

Edwards SAPIEN S3 was chosen as it is the only transcatheter valve available that can be reverse-mounted to accommodate the transapical approach. Additionally, the SAPIEN 3 valve provides the option of balloon hyperexpansion if needed to minimize the risk of migration and paravalvular leak, especially in the mitral position. The sequence of valve implantation is controversial. Salaun et al. [7] speculated that starting with mitral valve implantation may result in obstruction of the aortic prosthesis. Bauernschmitt et al. [5] chose to implant the mitral valve first due to the anatomical proximity and concern for compression of the smaller aortic valve while implanting the larger mitral prosthesis. In Elkharbotly's case [6], the aortic valve was placed first. In our case, the aortic valve was implanted first due to the critical nature of the aortic stenosis and in case of unexpected complications occurring during mitral valve intervention.

It is difficult to estimate the risk of mitral prosthesis migration. In the Bauernschmitt case [5], valve migration was not noted before the patient died from malignancy 9 months after implantation. In the Elkharbotly case [6], the reported 6-month follow-up was free of valve migration. Bapat et al. [8], in a valve-invalve case, reported the migration of a SAPIEN prosthesis from the mitral position. In our case, we decided to hyperexpand the balloon in the mitral position to maximize valve fixation and minimize the risk of migration. Hyperexpanding the mitral prosthesis may theoretically cause compression of the aortic valve or left ventricular outflow tract obstruction. Fortunately, the postdeployment left ventricular outflow tract gradient was only $12 \mathrm{mmHg}$.

In conclusion, simultaneous TAVR and TMVR for native aortic and mitral valve stenosis may be safe in highly selected inoperable patients. The long-term safety and outcome of simultaneous TAVR and TMVR are not known, and more investigation is needed to validate this approach.

\section{Conflict of Interest}

The authors have no conflict of interest relevant to this publication.

\section{Comment on this Article or Ask a Question}

\section{References}

1. Leon $M B$, Smith CR, Mack MJ, Miller CD, Moses JW, Lars S, et al. Transcatheter aortic-valve implantation for aortic stenosis in patients who cannot undergo surgery. N Eng J Med. 2010;363:1597-1507. DOI: 10.1056/NEJMoa1008232

2. Reardon MJ, Van Mieghem NM, Popma JJ, Kleiman NS, Sondergaard L, Mumtaz M, et al. Surgical or transcatheter aortic-valve replacement in intermediate-risk patients. N Eng J Med. 2017;376:1321-1331. DOI: 10.1056/NEJMoa1700456

3. Guerrero ME. Mitral Implantation of TRAnscatheter vaLves (MITRAL). ClinicalTrails. gov: NCT02370511

4. Gurrero $M$, Dvir $D$, Himbert $D$, Urene $M$, Eleid M, Greenbaum A, et al. Transcatheter mitral valve replacement in native mitral valve disease with severe mitral annular calcification: Results from the first multicenter global registry. JACC Cardiovascular Interv. 2016;9:1361-1371. DOI: 10.1016/j. jcin.2016.04.022

5. Bauernschmitt R, Bauer S, Liewald C, Emini $R$, Oechsner W, Beer $M$, et al. First successful transcatheter double valve replacement from a transapical access and nine-month follow up. Eurolntervention. 2017;17:16451648. DOI: 10.4244/EIJ-D-16-00896

6. Elkharbotly A, Delago A, El-Hajjar M. Simultaneous transapical transcatheter aortic valve replacement and transcatheter mitral valve replacement for native valvular stenosis. Catheter Cardiovasc Interv. 2016;87:1347-1351. DOI: 10.1002/ ccd. 26078

7. Salaun E, Pankert M, Habib G, Bonnet JL, Vahanian A, Himbert D, et al. How should I treat refractory cardiogenic shock in a patient with chronic biventricular heart failure and mitral regurgitation with difficult valve characteristics? Eurolntervention. 2016;11:1201-1206. DOI: 10.4244/ EIJV11110A238
8. Bapat VV, Khaliel F, Ihleberg L. Delayed migration of Sapien valve following a transcatheter mitral valve-in-valve implantation. Catheter Cardiovasc Interv. 2014;83: E150-E154. DOI: $10.1002 / c c d .25076$

Cite this article as: Tandar A, Glotzbach JP, Welt FG, Sharma V, Browning K, Selzman CH, Saidi A, Bull DA. Successful First-in-Man Concomitant Transapical Transcatheter Aortic and Mitral Valve Replacements for Severe Native Aortic and Mitral Valve Stenosis Using the Edwards Certitude Delivery System. Structural Heart Disease. 2017;3(6):180186. DOI: https://doi.org/10.12945/j. jshd.2017.026.17 


\section{Supplemental Media}

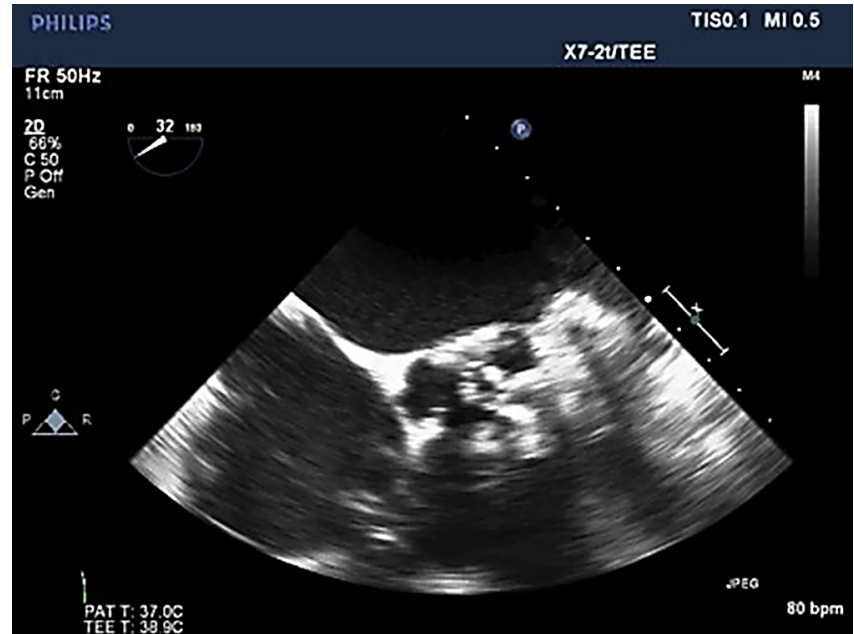

Video 1. Aortic valve pre-transcatheter aortic valve replacement. View supplemental video at https://doi.org/10.12945/j. jshd.2017.026.17.vid.01.

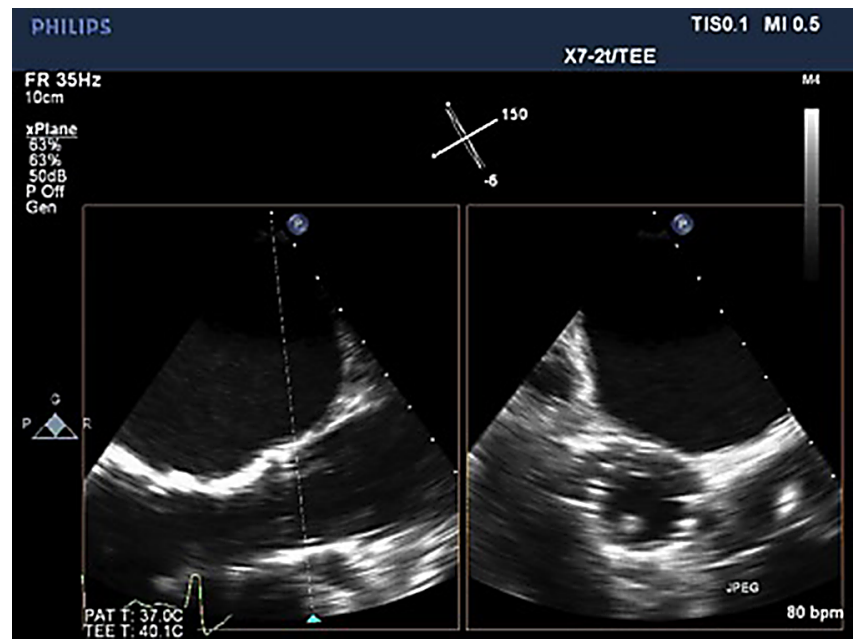

Video 2. Aortic valve post-transcatheter aortic valve replacement. View supplemental video at https://doi.org/10.12945/j. jshd.2017.026.17.vid.02.

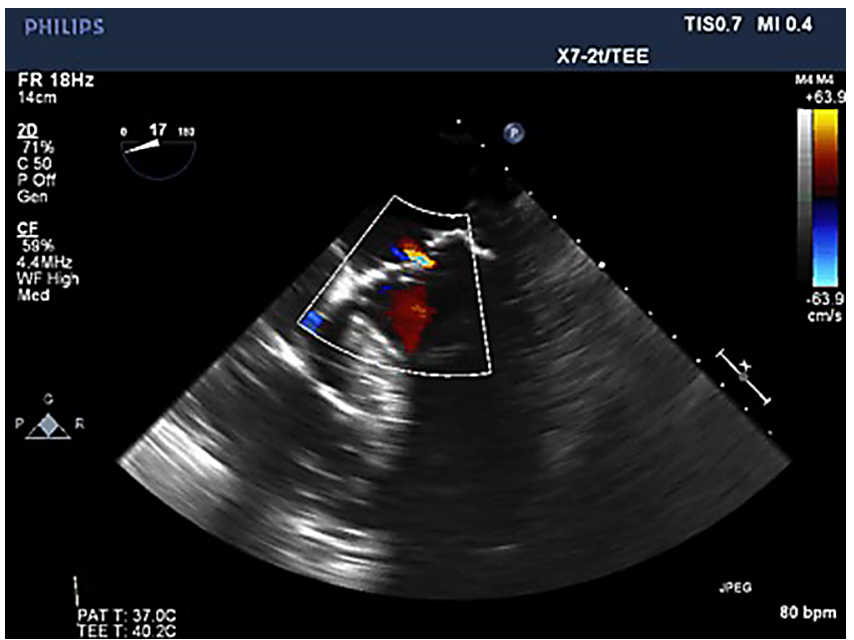

Video 3. Mitral stenosis pre-transcatheter mitral valve replacement. View supplemental video at https://doi.org/10.12945/j. jshd.2017.026.17.vid.03.

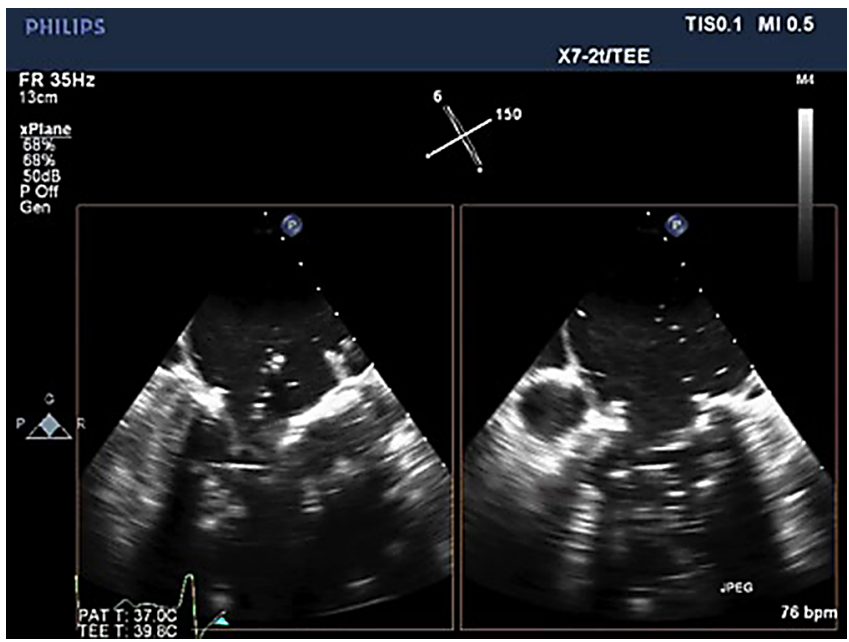

Video 4. Mitral valve post-transcatheter mitral valve replacement. View supplemental video at https://doi.org/10.12945/j. jshd.2017.026.17.vid.04. 


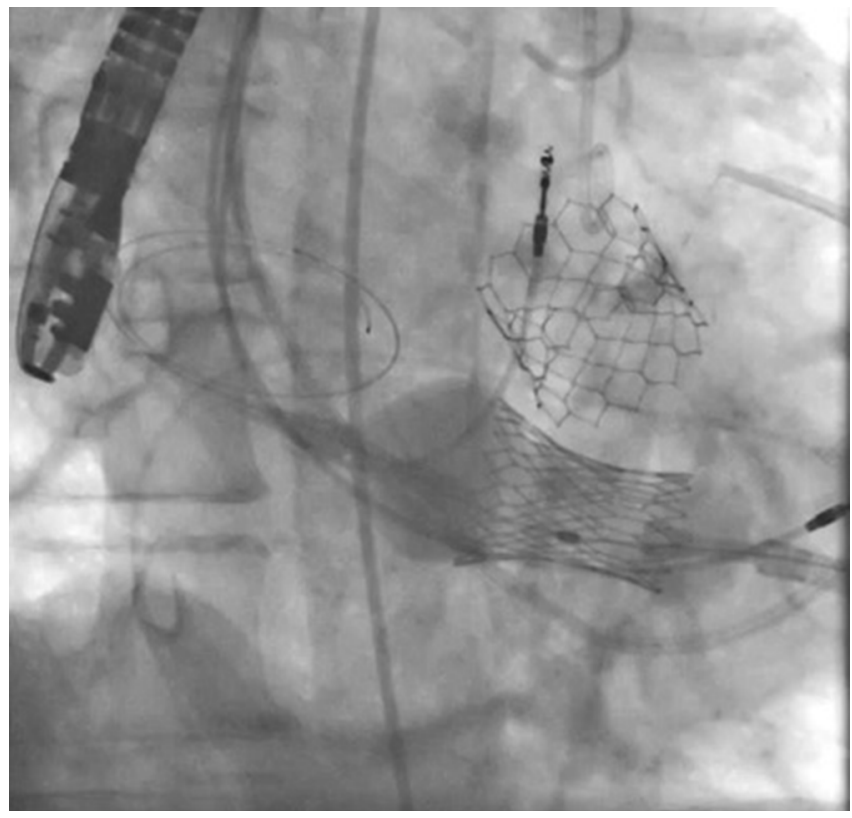

Video 5. Transapical transcatheter mitral valve replacement. View supplemental video at https://doi.org/10.12945/j. jshd.2017.026.17.vid.05.

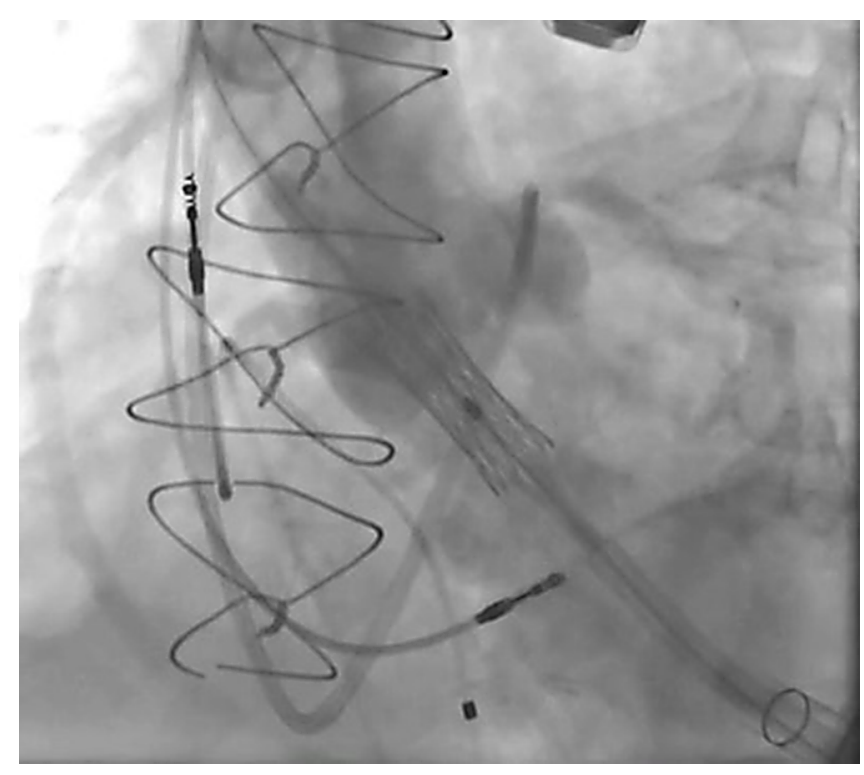

Video 6. Transapical transcatheter aortic valve replacement. View supplemental video at https://doi.org/10.12945/j. jshd.2017.026.17.vid.06. 